\title{
PLAGIARISM AND JMEP'S PUBLICATION ETHICS POLICY
}

In a popular cartoon by Marc Anderson (www.andertoons.com), a young student is shown defending an act of plagiarism in his schoolwork to his speechless school principal with the following reply, "I just figured plagiarism was that much more flattering than imitation." Unfortunately, for authors of professional publications such pious intentions seldom provide reprieve.

Now in its 26th year of publication, Journal of Materials Engineering and Performance has long used a statement on publication ethics under "Instructions for Authors" that outlines in very specific terms the behavior that is expected of submitting authors relative to the issue of plagiarism. It states, "Any material taken verbatim from another source

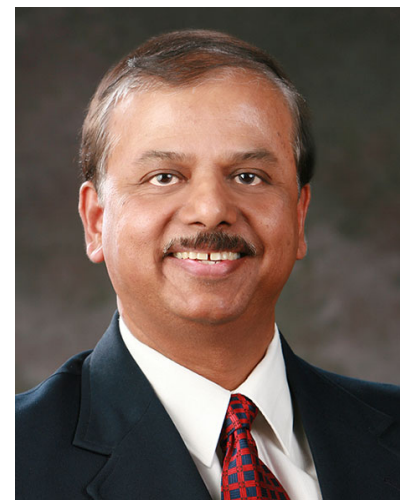
needs to be clearly identified to distinguish it from the present submission and the original source must be credited. Authors wishing to include figures, tables, or text passages that have already been published elsewhere are required to obtain permission from the copyright holder and to include evidence that such permission has been granted when submitting their papers."

Recently, JMEP established a separate policy to deal with the issue of plagiarism. The JMEP policy is similar to policies adopted by Journal of Thermal Spray Technology and Metallography, Microstructure, and Analysis. The policy was developed to deter plagiarism and outline the actions to be taken in responding to situations involving plagiarism. It also applies to situations of self-plagiarism that attempt to gain an additional publication for authors through incremental revision of another publication. The policy is meant to deter acts of plagiarism and apprise the authors of the journal's expectations. It states in clear terms that deliberate acts of plagiarism and similar misconduct shall be duly reprimanded. The policy is included in this issue and posted on the journal's Web site.

All manuscripts submitted to JMEP are automatically checked for potential plagiarism using a plagiarism detection software. Depending on the score received, a manuscript may be red-flagged. A more comprehensive evaluation of the content by the editorial staff is then used to determine whether the paper merits technical review by external referees. Plagiarism might also be identified during the review process by referees. Unlike the humanities, where the quality of the writing might add or detract from the content, a separation of the content from the language used to express the content is usually feasible for engineering disciplines. This is given due consideration when interpreting the score a manuscript receives on our plagiarism detection software. Our goal is to examine each situation on a case-by-case basis to remain fair to our authors while preserving the integrity of the scholarly publication process.

JMEP's policy on plagiarism was developed from the policies of Metallography, Microstructure, and Analysis journal and Journal of Thermal Spray Technology (JTST). Additionally, guidance from Mary Anne Fleming, ASM's Senior Content Developer, was critical in shaping JMEP's policy. Questions about the plagiarism policy for JMEP may be directed to the journal Editor at asthanar@uwstout.edu.

\section{Rajiv Asthana}

Editor

University of Wisconsin-Stout, Menomonie, WI

Contact e-mail: asthanar@uwstout.edu 